\title{
Anti-CD123-Pyrrolobenzodiazepine Dimer Antibody Drug Conjugate SGN-CD123A
}

National Cancer Institute

\section{Source}

National Cancer Institute. Anti-CD123-Pyrrolobenzodiazepine Dimer Antibody Drug

Conjugate SGN-CD123A. NCI Thesaurus. Code C129457.

An antibody-drug conjug ate (ADC) consisting of an anti-CD123 humanized monoclonal antibody conjug ated, via a stable maleimidocaproyl-valine-alanine dipeptide proteasecleavable linker, to the cytotoxic, DNA minor-groove crosslinking agent pyrrolobenzodiazepine (PBD) dimer, with potential antineoplastic activity. Upon administration of anti-CD123 ADC SGN-CD123A, the antibody moiety targets the cell surface antigen CD123. Upon antibody/antigen binding, internalization, and lysosome uptake, the cytotoxic PBD moiety is released. In turn, the imine groups of the PBD moiety bind to the N2 positions of guanines on opposite strands of DNA. This induces DNA strand breaks, inhibits DNA replication, leads to G2/M cell cycle arrest, induces cell death, and inhibits the proliferation of CD123-overexpressing tumor cells. CD123, the alpha subunit of the IL-3 receptor, regulates the proliferation, survival and differentiation of hematopoietic cells. CD123 is overexpressed on a variety of cancers, including myeloid leukemia, and increased expression of CD123 on leukemic stem cells is associated with poor prognosis. Cysteine eng ineering of the monoclonal antibody (EC-mAb) allows for a site-specific, stable conjug ation and uniform loading of the PBD agent to the antibody. 